\title{
Effect of substrate temperature on structural, morphological and optical properties of deposited $\mathrm{Al} / \mathrm{ZnO}$ films
}

\author{
Z. Ghorannevis • M. T. Hosseinnejad • \\ M. Habibi • P. Golmahdi
}

Received: 28 July 2014/Accepted: 3 November 2014/Published online: 10 December 2014

(C) The Author(s) 2014. This article is published with open access at Springerlink.com

\begin{abstract}
Al}$-doped $\mathrm{ZnO}(\mathrm{Al} / \mathrm{ZnO})$ thin film is a promising alternative to an ITO electrode in solar cell applications due to its low price, non-toxicity and other promising properties. In this paper, $\mathrm{Al} / \mathrm{ZnO}$ thin films at different substrate temperatures were deposited on glass substrates as transparent conducting (TCO) films by DC magnetron sputtering. The effect of substrate temperature on the structural, morphological and optical properties of $\mathrm{Al} / \mathrm{ZnO}$ films was investigated. X-ray diffraction (XRD) analysis suggests that crystal structure characteristics of synthesized thin films depend on the substrate temperature. The structure growth and variation in surface roughness with increasing substrate temperature are revealed by scanning electron microscope (SEM) micrographs and atomic force microscopy (AFM) analyses. Thicknesses of the deposited films were also examined by surface profiler. Moreover, obtained results from optical transmission patterns revealed that with the increasing substrate temperature, optical transmittance decreases.
\end{abstract}

Z. Ghorannevis $(\bowtie)$

Department of Physics, Karaj Branch, Islamic Azad University, Karaj, Iran

e-mail: z.ghorannevis@kiau.ac.ir

M. T. Hosseinnejad · M. Habibi

Plasma Physics Research Center, Science and Research Branch, Islamic Azad University, Tehran, Iran

M. T. Hosseinnejad

Young Researchers and Elites Club, Science and Research Branch, Islamic Azad University, Tehran, Iran

P. Golmahdi

Department of Physics, Science and Research Branch, Islamic

Azad University, Fars, Iran
Keywords Sputtering - Thin film · Transparent conducting oxide $\cdot$ SEM $\cdot$ AFM

\section{Introduction}

Transparent conductive oxides (TCO) are widely used in various applications in many optoelectronic devices, such as solar cells, LCDs, optical waveguide, surface acoustic wave (SAW) devices, blue or ultra-violet (UV) LEDs, laser diodes (LD), light emitting diodes, gas sensor and different other devices [1-5].

The application of TCO in crystalline silicon solar cells passivates the surface and reduces the probability of emitter shunting through holes [1]. Nowadays, the most applicable material for the transparent electrodes fabrication is tin-doped indium oxide (ITO).

But the high cost of indium necessitates the research in the field of creation and characterization of the materials for the ITO substitution. The zinc oxide with a wide band gap $(3.37 \mathrm{eV})$ n-type semiconductor and high exciton binding energy $(60 \mathrm{meV})$ at room temperature is actively studied as a material that could replace ITO, because $\mathrm{ZnO}$ is a widespread, inexpensive and non-toxic material. Impurity doping of $\mathrm{ZnO}$ with the elements of the third group of the periodic table (boron, aluminium, gallium and indium) produces n-type conductivity due to $\mathrm{Zn}^{+2}$ ion substitution [6-10]. The most perspective materials for $\mathrm{ZnO}$ doping are $\mathrm{Al}(\mathrm{Al} / \mathrm{ZnO})$ [9] and $\mathrm{Ga}(\mathrm{Ga} / \mathrm{ZnO})$ [10] because of the high solubility and behaviour during the growth, which allows obtaining the films of low resistivity $\left(\sim 10^{-4} \mathrm{Ohm} \times \mathrm{cm}\right)$ and high transparency in the visible region of the spectrum [11-14]. Meanwhile, $\mathrm{Al} / \mathrm{ZnO}$ would be more preferable for industrial use due to the relatively low cost of the initial components. A principal interest in 
the study of these materials is caused by the dependence of their physical properties (band gap, concentration and mobility of charge carriers, transmittance, etc.) on the fabrication conditions [15-18]. In terms of the literature data, there are no definitive recommendations for the highquality $\mathrm{Al} / \mathrm{ZnO}$ and $\mathrm{Ga} / \mathrm{ZnO}$ films synthesis.

Therefore, the research in this field (the influence of the growth parameters, and subsequent heat treatment on the properties and the stability of the films) is intensively conducted [19-22]. $\mathrm{Al} / \mathrm{ZnO}$ is easy to fabricate with various deposition methods, e.g. thermal evaporation [17], chemical vapour deposition (CVD) [18], plasma-enhanced chemical vapour deposition (PECVD) [19], sol-gel [20], spray pyrolysis [21], and magnetron sputtering [22, 23]. Among sputtering methods, continuous direct current (dc) magnetron sputtering is the simplest and has many advantages such as a higher deposition rate and an easier operation than radio frequency magnetron sputtering. RF sputtering gave better resistivity and transparency than $\mathrm{dc}$ in most of cases. This paper reports the study of the $\mathrm{Al} / \mathrm{ZnO}$ thin films' properties, which depends on the film thickness, which can be varied by changing a substrate temperature. The effect of substrate temperature is investigated on the structural, morphological and the optical properties of the $\mathrm{Al} / \mathrm{ZnO}$-deposited thin films.

\section{Experimental setup}

$\mathrm{Al} / \mathrm{ZnO}$ thin films were deposited on glass substrates using direct current $(\mathrm{dc})$ magnetron sputtering system. Figure 1 shows a schematic of the DC magnetron sputtering setup, which was used in these experiments.

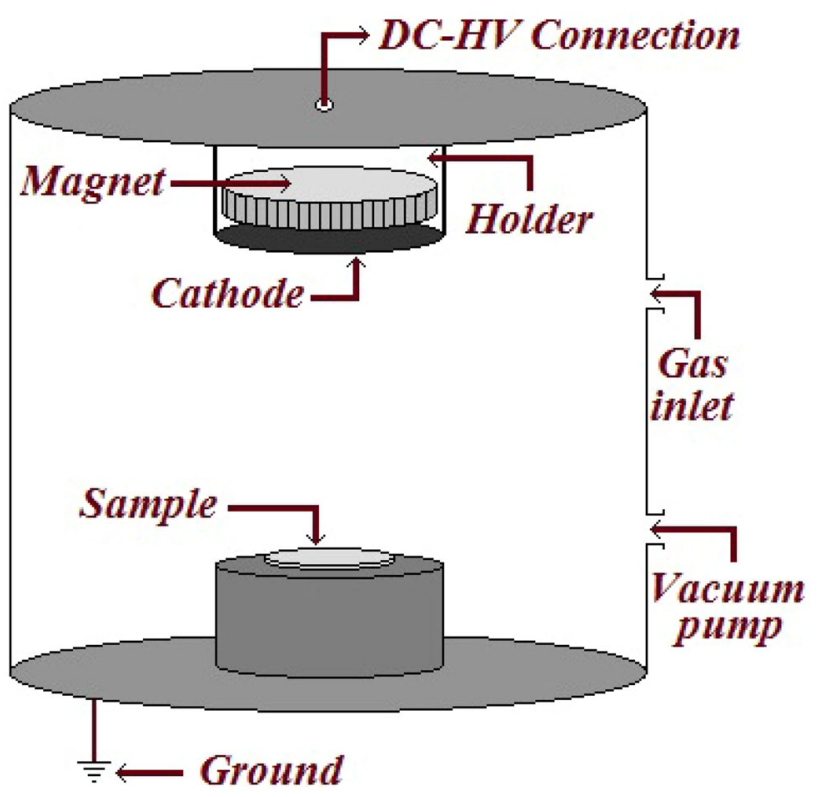

Fig. 1 Schematic of DC magnetron sputtering system
The base pressure in the chamber was $5 \times 10^{-5} \mathrm{mbar}$ by a turbo pump (Hind High Vacuum, H.H.V, 12"MSPT), and the working pressure was $1.6 \times 10^{-2}$ mbar. The working gas was $99.9 \%$ Ar purified and a circular flat disc (thickness $3 \mathrm{~mm}$, and diameter $290 \mathrm{~mm}$ ) made of $2 \mathrm{wt} \%$ alumina in stoichiometric $\mathrm{ZnO}$ was employed as the sputtering target. A continuous dc power supply was used, whereas current and voltage were fixed at $13 \mathrm{~mA}$ and $10 \mathrm{~V}$, respectively. Also the distance between a target and a substrate was $3 \mathrm{~cm}$ for all the samples.

Before the deposition, the plasma discharge was run. Deposition conditions and discharge current were optimized to obtain continuous and uniform thin films with the different thicknesses. All samples were deposited using similar experimental conditions. Glass substrates were ultrasonically cleaned, first using alcohol for a period of $5 \mathrm{~min}$, then acetone for $10 \mathrm{~min}$. The crystalline structures of the films were determined using a Philips diffractometer (Xpert pw3373), $\left(\mathrm{Cu} \mathrm{K} \alpha\right.$ radiation) with a step size of $0.02^{\circ}$ and count time of $1.0 \mathrm{~s}$ per step. Morphological properties of deposited samples were investigated by scanning electron microscopy (SEM, Hitachi S-4160) and atomic force microscopy (AFM, Auto Probe Pc; in contact mode, with low stress silicon nitride tip of less than $200 \mathrm{~A}^{\circ}$ radius and tip opening of $18^{\circ}$ ) analysis. Moreover, optical properties of thin films were determined using UV/VIS spectrophotometer (Varian, 500 scan vary) in the spectral range of 200 to $800 \mathrm{~nm}$.

\section{Results and discussion}

The XRD patterns of $\mathrm{Al} / \mathrm{ZnO}$ thin films deposited at different substrate temperatures ( 150 to $350{ }^{\circ} \mathrm{C}$ ) using $\mathrm{Al} /$ $\mathrm{ZnO}$ target are shown in Fig. 2. The material was scanned in the range of $10^{\circ}-80^{\circ}$.

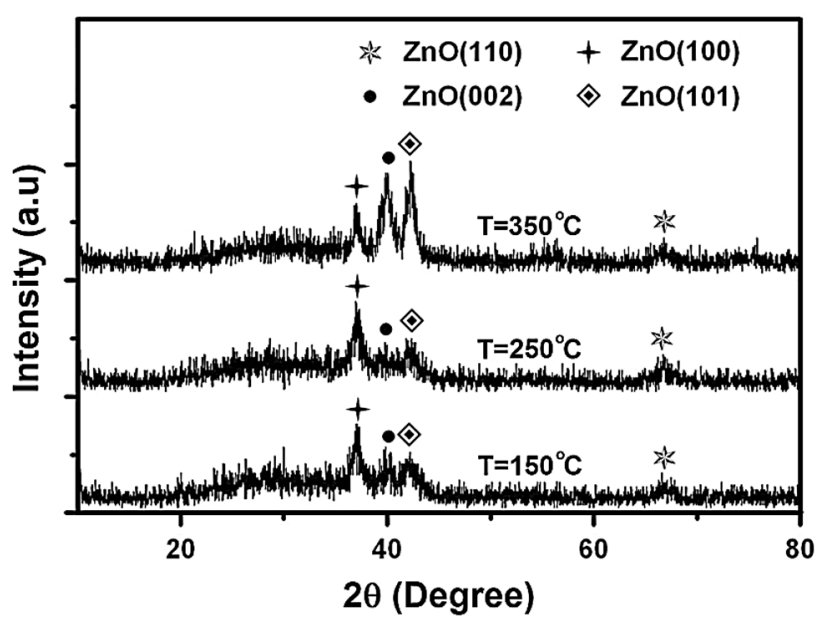

Fig. 2 The XRD patterns of the deposited thin films at different substrate temperatures 
These patterns evidence emergence of $\mathrm{ZnO}$ crystalline phase on glass substrates for all samples deposited at various substrate temperatures. The diffraction peaks of $\mathrm{ZnO}$ $\left(\begin{array}{lll}1 & 0 & 0\end{array}\right), \mathrm{ZnO}\left(\begin{array}{lll}0 & 0 & 2\end{array}\right), \mathrm{ZnO}\left(\begin{array}{lll}1 & 0 & 1\end{array}\right)$ and $\mathrm{ZnO}\left(\begin{array}{lll}1 & 1 & 0\end{array}\right)$ crystalline planes are observed. The respective locations of all $\mathrm{ZnO}$ diffraction peaks are in suitable agreement with the Joint Committee for Powder Diffraction Standards (JCPDS) standard data.

From XRD analysis, we observe that even if the respective locations of all diffraction peaks are same for all deposited samples but the peak intensities vary with increasing the substrate temperature. Therefore, the degree of crystallinity of deposited thin films strongly depends on substrate temperature.

Figure 3 shows the SEM micrographs of $\mathrm{Al} / \mathrm{ZnO}$ thin films deposited using different substrate temperatures. The
SEM micrographs of the prepared samples with different substrate temperatures exhibit the crystalline growth structures by increasing the substrate temperatures.

Higher magnification images suggest that they are the conglomerates of many smaller sized grains in the samples. The conglomeration of smaller size grains can be activated by greater energy due to the increasing substrate temperature which causes more mobility of nanoparticles and hence resulting in the larger sized structures. The surface morphology of the deposited thin films in Fig. 3 shows more heterogeneous distribution of grains with the increase in the substrate temperature that may be due to the more grains growth.

Results obtained from SEM analysis show that the energy of the ions plays an important role on the film surface morphologies. The cross-sectional SEM images of

Fig. 3 Top and cross-sectional views of $\mathrm{Al} / \mathrm{ZnO}$ thin films prepared at a $150{ }^{\circ} \mathrm{C} \mathrm{b} 250{ }^{\circ} \mathrm{C}$ and c $350{ }^{\circ} \mathrm{C}$ substrate temperatures

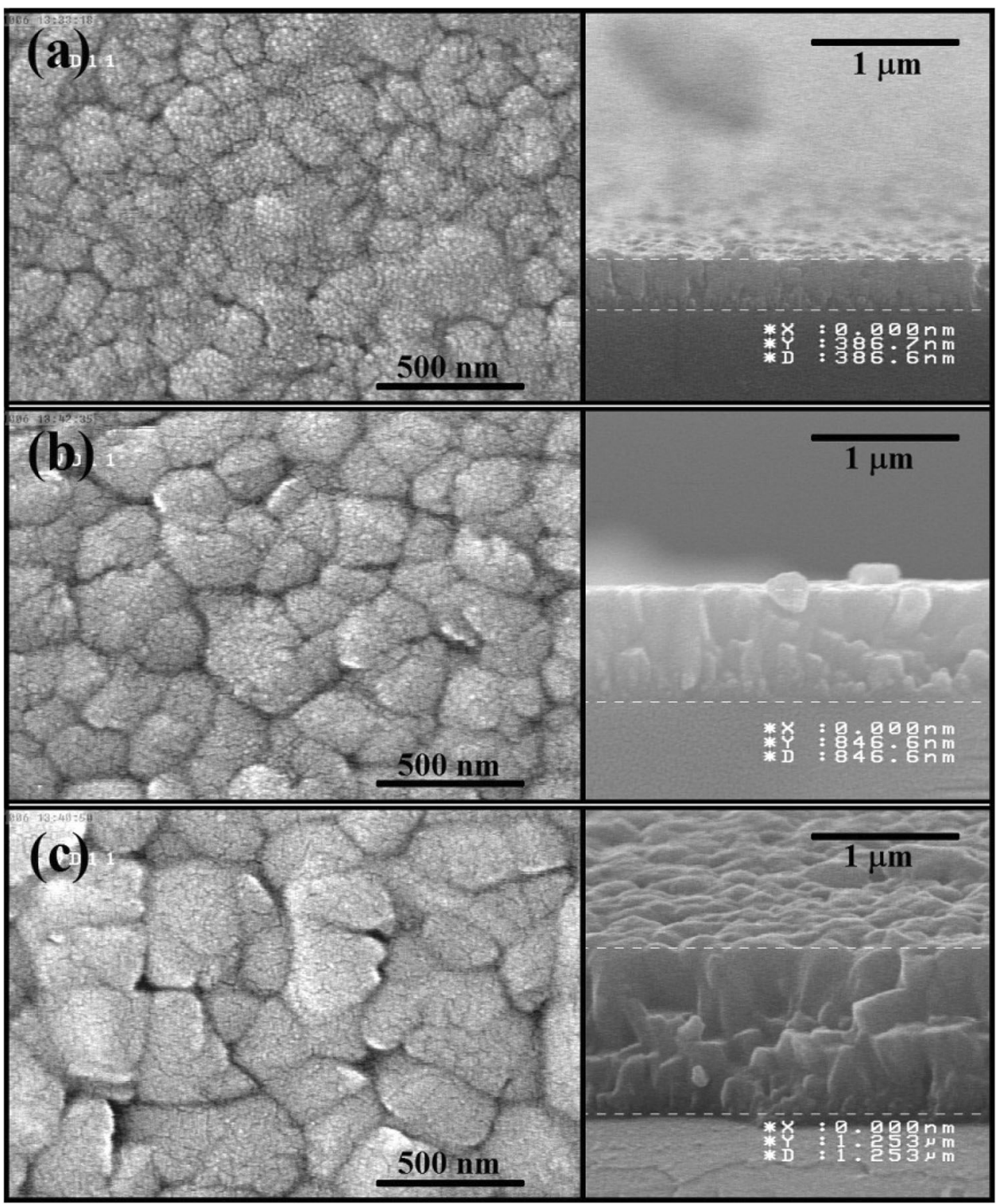


Table 1 The average thickness of deposited samples at different substrate temperatures

\begin{tabular}{lc}
\hline Substrate temperatures $\left({ }^{\circ} \mathrm{C}\right)$ & Average thickness $(\mathrm{nm})$ \\
\hline 150 & 380 \\
250 & 840 \\
350 & 1240 \\
\hline
\end{tabular}

the samples prepared at different substrate temperatures are given in Fig. 3. As it can be seen from Fig. 3, when the substrate temperature increases from $250^{\circ}$ to $350^{\circ}$ thickness of the deposited thin films also increases.

The thicknesses of deposited samples are tested with surface profiler with the accuracy of $10 \mathrm{~nm}$ (Dektak 3030, Veeco instruments Inc.). The average thickness of the obtained samples is presented in Table 1. Results shown in Table 1 indicate that thickness of the deposited films with various substrate temperatures is in good agreement with the obtained results from the cross-sectional SEM images.

The surface morphologies of the samples, which were deposited at various substrate temperatures, were examined by AFM. The 2D and 3D surface topographies of the deposited thin films are shown in Fig. 4. All the images have been obtained with a scanning area of $5 \mu \mathrm{m} \times 5 \mu \mathrm{m}$.

The 2D and 3D surface topographies of the thin films prepared show that distributions of the grains on the sample surfaces are observed to be more heterogeneous with increasing the substrate temperature. AFM images showed that by increasing the substrate temperature the size of the grains/clusters on the surface of thin films increases (see Fig. $4 a-c)$.

Fig. 4 2D and 3D AFM images of AZO films deposited at (a) $150{ }^{\circ} \mathrm{C}$ (b) $250{ }^{\circ} \mathrm{C}$ and (c) $350{ }^{\circ} \mathrm{C}$ substrate temperatures
This result is perfectly consistent with the previous conclusion that the crystalline growth of $\mathrm{Al} / \mathrm{ZnO}$ structures increases by increasing the substrate temperature, which was observed from our SEM results.

Surface roughness is one of the important properties of the $\mathrm{Al} / \mathrm{ZnO}$ thin films for many optoelectronics applications, because the level of surface roughness will dominate the carrier mobility and light scattering and the smooth structure can reduce the scattering of incident light, which makes the contribution to increase the transmittance [24]. In this work, to analyse and compare the surface roughnesses of the prepared thin films, the roughness of four random areas over the surface of the deposited thin film was measured, and the average and root mean square (rms) values of the measurements were recorded. The recorded rms and average values of the roughness measurements are given in Table 2.

As it can be seen from the Table 2, by increasing the substrate temperature, more roughness is observed on the surface of the deposited $\mathrm{Al} / \mathrm{ZnO}$ thin films.

This is predictable because, as it was already mentioned, with increasing the substrate temperature, the size of the grains becomes larger on the surface of the films, which will lead to increasing the roughness of the deposited thin films.

Figure 5 shows the optical transmission spectra of $\mathrm{Al} /$ $\mathrm{ZnO}$ thin films at different substrate temperatures in the wavelength range from 300 to $900 \mathrm{~nm}$. All films have an average transmittance over $90 \%$ in the visible region. The absorption edge of $\mathrm{Al} / \mathrm{ZnO}$ thin films corresponds to electron transitions from valance band to conduction band.
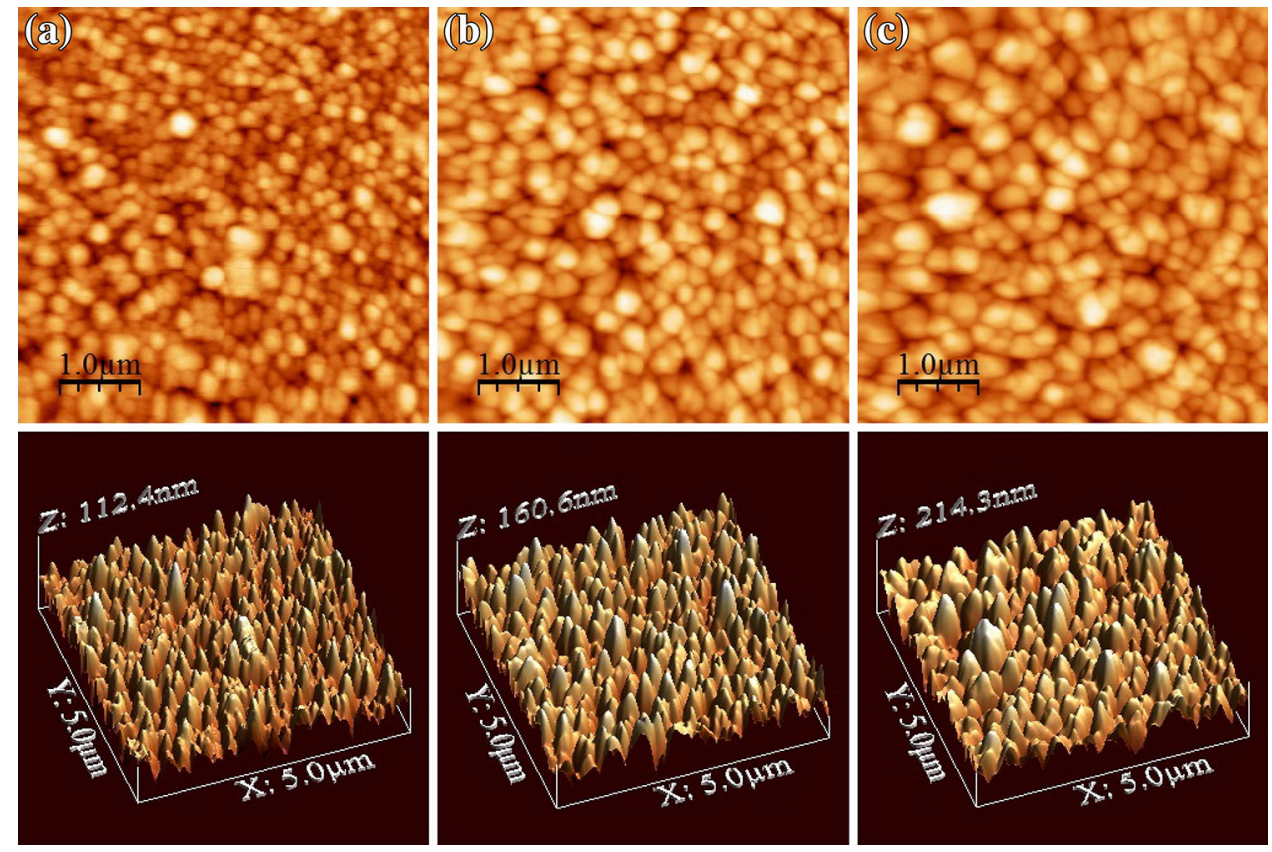
Table 2 Average and rms surface roughness of thin films deposited at different substrate temperatures

\begin{tabular}{llll}
\hline Substrate temperatures $\left({ }^{\circ} \mathrm{C}\right)$ & 150 & 250 & 350 \\
\hline RMS Roughness (nm) & 15.1 & 22.4 & 27.6 \\
Ave. Roughness (nm) & 12.1 & 17.9 & 21.9 \\
\hline
\end{tabular}

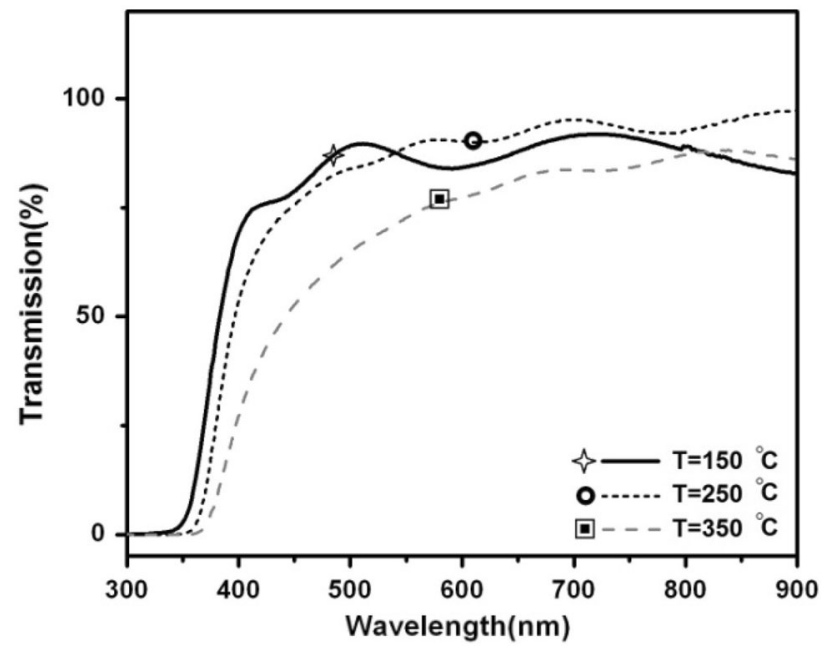

Fig. 5 Optical transmittance spectra of deposited $\mathrm{Al} / \mathrm{ZnO}$ thin films at different substrate temperatures

Table 3 Variation of energy band gap for samples prepared with different substrate temperatures

\begin{tabular}{ll}
\hline Substrate temperatures $\left({ }^{\circ} \mathrm{C}\right)$ & Band gap $(\mathrm{eV})$ \\
\hline 150 & 3.33 \\
250 & 3.35 \\
350 & 3.38 \\
\hline
\end{tabular}

From Fig. 5, the band gap energies of the $\mathrm{Al} / \mathrm{ZnO}$ films can be determined by the following Eq. [25]:

$A h v=\left(h v-E_{\mathrm{g}}\right)^{1 / 2}$

where $E_{\mathrm{g}}$ is the optical band gap and $\mathrm{h} v$ is the photon energy. The absorption coefficient $\alpha$ was obtained from the transmittance data using the relation $\alpha=(1 / d) \ln (1 / T)$, where $d$ and $T$ are the thickness and the transmittance of the films, respectively. The values of band gap energies for deposited samples with different substrate temperatures are given in Table 3.

As it can be seen from the Table 3, the optical band gap energy increases from 3.33 to $3.38 \mathrm{eV}$ with increasing the substrate temperature, which can be due to the increase in thin films thicknesses with increasing the substrate temperature.

\section{Conclusion}

A systematic study has been performed to investigate the effect of substrate temperatures in the DC magnetron sputtering treatment on the growth behaviour of $\mathrm{Al} / \mathrm{ZnO}$ thin films on the glass substrate. $\mathrm{Al} / \mathrm{ZnO}$ thin films were deposited at different substrate temperatures by keeping other experimental parameters such as working pressure, target to substrate distance and deposition times. Deposited samples were studied and compared for various characteristics using different techniques like XRD, SEM and AFM analyses. The XRD results suggested that the degree of crystallinity of the deposited thin films strongly changes with increasing the substrate temperature. SEM images of the deposited samples at various substrate temperatures revealed the presence of nano/sub-micro structures and their agglomeration by increasing the substrate temperature. It is found that the average thickness of the deposited thin films also increases by increasing the substrate temperatures. Obtained results from AFM analysis show that increase in the substrate temperature leads to increasing the size of the grains on the surface of thin films. Also AFM results reveal that more roughness can be observed on the surface of the deposited thin films for higher substrate temperatures. On the other hand, spectrophotometry results show that the band gap energy also increases by increasing the substrate temperature. The highest transparency was obtained for the sample with higher deposition time, which was $95 \%$.

Open Access This article is distributed under the terms of the Creative Commons Attribution License which permits any use, distribution, and reproduction in any medium, provided the original author(s) and the source are credited.

\section{References}

1. Untila, G.G., Kost, T.N., Chebotareva, A.B., Zaks, M.B., Sitnikov, A.M., Solodukha, O.I.: Effect of conditions of deposition and annealing of indium oxide films doped with fluorine (IFO) on the photovoltaic properties of the IFO/p-Si heterojunction. Semiconductors 42, 406-413 (2008)

2. Yen, W.T., Lin, Y.C., Ke, J.H.: Surface textured ZnO:Al thin films by pulsed DC magnetron sputtering for thin film solar cells applications. Appl. Surf. Sci. 257, 960-968 (2010)

3. Huang, H., Fang, G., Li, S., Long, H., Mo, X., Wang, H.: Ultraviolet/orange bicolor electroluminescence from an $\mathrm{n}-\mathrm{ZnO} / \mathrm{n}$ GaN isotype heterojunction light emitting diode. Appl. Phys. Lett. 99, 263502 (2011)

4. Bao, J., Zimmler, M.A., Capasso, F., Wang, X., Ren, Z.F.: Broadband $\mathrm{ZnO}$ single-nanowire light-emitting diode. Nano Lett. 6, 1719-1722 (2006)

5. Shirazi, M., Hosseinnejad, M.T., Zendehnam, A., Ghoranneviss, M., Etaati, G.R.: Synthesis and characterization of nanostructured $\mathrm{ZnO}$ multilayer grown by DC magnetron sputtering. J. Alloys Comp. 602, 108-116 (2014)

6. Choi, B.G., Kim, I.H., Kim, D.H., Lee, K.S., Lee, T.S., Cheong, B., Baik, Y.J., Kim, W.M.: Electrical, optical and structural properties of transparent and conducting $\mathrm{ZnO}$ thin films doped with $\mathrm{Al}$ and $\mathrm{F}$ by rf magnetron sputter. J. Eur. Ceram. Soc. 25, 2161-2165 (2005)

7. Lin, J.C., Peng, K.C., Yeh, T.Y., Lee, S.L.: On the structure and characterization of Al, Sc-co-doped $\mathrm{ZnO}$-films varying with 0-2.37 wt.\% Sc contents. Thin Solid Films 517, 4715-4719 (2009) 
8. Kim, Y.H., Lee, K.S., Lee, T.S., Cheong, B., Seong, T.Y., Kim, W.M.: Effects of substrate temperature and $\mathrm{Zn}$ addition on the properties of Al-doped $\mathrm{ZnO}$ films prepared by magnetron sputtering. Appl. Surf. Sci. 255, 7251-7256 (2009)

9. Pan, Z., Tian, X., Wu, S., Yu, X., Li, Z., Deng, J.: Investigation of structural, optical and electronic properties in Al-Sn co-doped ZnO thin films. Appl. Surf. Sci. 265, 870-877 (2013)

10. Bhosle, V., Tiwari, A., Narayan, J.: Metallic conductivity and metal-semiconductor transition in Ga-doped ZnO. Appl. Phys. Lett. 88, 0321061 (2006)

11. Ataev, B.M., Bagamadova, A.M., Djabrailov, A.M., Mamedov, V.V., Rabadanov, R. A.: Highly conductive and transparent Gadoped epitaxial ZnO films on sapphire by CVD. Thin Solid Films 260, 19-20 (1995)

12. Chen, M., Pei, Z., Xi, W., Sun, C., Wen, L.: Transparent conductive oxide semiconductor $\mathrm{ZnO}$ :Al films produced by magnetron reactive sputtering. Mat. Res. Soc. Symp. Proc. 666, F1.2 (2001)

13. Ko, H.J., Chen, Y.F., Hong, S.K., Wenisch, H., Yaoand, T., Look, D.C.: Ga-doped $\mathrm{ZnO}$ films grown on $\mathrm{GaN}$ templates by plasmaassisted molecular-beam epitaxy. Appl. Phys. Lett. 77, 3761 (2000)

14. Hou, Y., Soleimanpour, A.M., Jayatissa, A.H.: Low resistive aluminum doped nanocrystalline zinc oxide for reducing gas sensor application via sol-gel process. Sens. Actuators B 177, 761-769 (2002)

15. Ozgur, U., Alivov, Ya.I., Liu, C., Teke, A., Reshchikov, M.A., Dogan, S., Avrutin, V., Cho, S.J., Morkoc, H.: A comprehensive review of ZnO materials and devices. J. Appl. Phys. 98, 041301-1 (2005)

16. Sernelius, B.E., Berggren, K.F., Jin, Z.C., Hambergand, I., Granqvist, C.G.: Band-gap tailoring of $\mathrm{ZnO}$ by means of heavy Al doping. Phys. Rew. B. 37, 10244 (1988)
17. Lu, J.G., Fujita, S., Kawaharamura, T., Nishinaka, H., Kamada, Y., Ohshima, T., Ye, Z.Z., Zeng, Y.J., Zhang, Y.Z., Zhu, L.P., He, H.P., Zhao, B.H.: Carrier concentration dependence of band gap shift in -type ZnO:Al films. J. Appl. Phys. 101, 083705-1 (2007)

18. Ginley, D.S., Hosono, H., Paine, D.C. (eds.): Handbook of Transparent Conductors. Springer, New York (2010)

19. Ohta, N., Ohba, D., Sato, S., Tang, Z., Shimizu, H., Shirai, H.: Rapid thermal-plasma annealing of $\mathrm{ZnO}$ :Al films for silicon thinfilm solar cells. Thin Solid Films 519, 6920-6927 (2011)

20. Yen, W.T., Lin, Y.C., Yao, P.C., Ke, J.H., Chen, Y.L.: Effect of post-annealing on the optoelectronic properties of $\mathrm{ZnO}$ :Ga films prepared by pulsed direct current magnetron sputtering. Thin Sol. Films 518, 3882-3885 (2010)

21. Vigil, O., Cruz, F., Santana, G., Vaillant, L., Morales-Acevedo, A., Contreras-Puente, G.: Influence of post-thermal annealing on the properties of sprayed cadmium-zinc oxide thin films. Appl. Surf. Sci. 161, 27-34 (2000)

22. Kelly, P.J., Arnell, R.D.: Magnetron sputtering: a review of recent developments and applications. Vacuum 56, 159-172 (2000)

23. Ko, H., Tai, W.P., Kim, K.C., Kim, S.J., Suh, S.H., Kim, Y.S.: Growth of Al-doped $\mathrm{ZnO}$ thin films by pulsed DC magnetron sputtering. J. Cryst. Growth 277, 352-358 (2005)

24. Suchea, M., Christoulakis, S., Katsarakis, N., Kitsopoulos, T., Kiriakidis, G.: Comparative study of zinc oxide and aluminum doped zinc oxide transparent thin films grown by direct current magnetron sputtering. Thin Solid Films 515, 6562-6566 (2007)

25. Tauc, J., Grigorovici, R., Vancu, A.: Optical properties and electronic structure of amorphous germanium. Phys. Stat. Sol. 15, 627-637 (1966) 